\title{
Analysis and experimental verification of multi-band thin monopole antennas loaded with half-mode CRLH-inspired resonators
}

DOI:

10.1080/09205071.2018.1466729

\section{Document Version}

Accepted author manuscript

Link to publication record in Manchester Research Explorer

Citation for published version (APA):

Abdalla, M. A., \& Hu, Z. (2018). Analysis and experimental verification of multi-band thin monopole antennas loaded with half-mode CRLH-inspired resonators. Journal of Electromagnetic Waves and Applications, 1-13. https://doi.org/10.1080/09205071.2018.1466729

Published in:

Journal of Electromagnetic Waves and Applications

\section{Citing this paper}

Please note that where the full-text provided on Manchester Research Explorer is the Author Accepted Manuscript or Proof version this may differ from the final Published version. If citing, it is advised that you check and use the publisher's definitive version.

\section{General rights}

Copyright and moral rights for the publications made accessible in the Research Explorer are retained by the authors and/or other copyright owners and it is a condition of accessing publications that users recognise and abide by the legal requirements associated with these rights.

\section{Takedown policy}

If you believe that this document breaches copyright please refer to the University of Manchester's Takedown Procedures [http://man.ac.uk/04Y6Bo] or contact uml.scholarlycommunications@manchester.ac.uk providing relevant details, so we can investigate your claim.

\section{OPEN ACCESS}




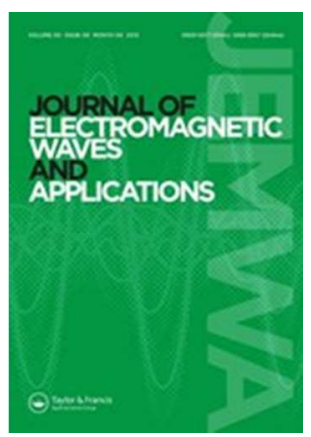

\section{Analysis and Experimental Verification of Multi Band Thin Monopole Antennas Loaded with Half Mode CRLH Inspired Resonators}

\begin{tabular}{|r|l|}
\hline Journal: & Journal of Electromagnetic Waves and Applications \\
\hline Manuscript ID & TEWA-2017-0056.R3 \\
\hline Manuscript Type: & Original Article \\
\hline Keywords: & $\begin{array}{l}\text { Metamaterial, Half mode-CRLH., Dual / Triple Multi-band antenna, } \\
\text { Monopole Antenna }\end{array}$ \\
\hline \multicolumn{2}{|l}{} \\
\hline
\end{tabular}

\section{SCHOLARONE" \\ Manuscripts}




\section{$\underline{\text { Reply to Reviewer 1's Comments: }}$}

Reviewer(s)' Comments to Author:

It seems the paper has too many self citations, which the authors are strongly suggested to eliminate.

\section{Reply:}

Some references were added to demonstrate the authors experience in the paper topic. However, to meet the reviewer comment, in the revised manuscript, self references from [33]-[39] were deleted and replaced by only [7] in citing in page 3. Hence, the self references have been reduced from 14 to 7 only. 


\section{Analysis and Experimental Verification of Multi Band Thin Monopole Antennas Loaded with Half Mode CRLH Inspired Resonators}

Keywords: Metamaterial, Dual / Triple Multi-band antenna, Half mode-CRLH.

This paper presents analysis and experimental measurements of CPW and microstrip compact monopole antennas loaded with resonator circuits inspired from simplified half mode composite right / left handed unit cell. The antennas were designed to have a typical omnidirectional radiation pattern. The CPW fed dual band antenna resonats at 2.4 GHz and $5.8 \mathrm{GHz}$, respectively. The antenna size is $20 \times 30 \mathrm{~mm}^{2}$ and the radiator patch is only $25 \%$ at $2.4 \mathrm{GHz}$ and $60 \% 5.8 \mathrm{GHz}$ in comparison with a conventional patch antenna. The microstrip triple band antenna covers the frequency bands from 2 GHz-2.4 GHz, 5.4 GHz-6 GHz, and $6.8 \mathrm{GHz}-8 \mathrm{GHz}$. The antenna size is 28 × $25 \mathrm{~mm}^{2}$ which is less than $25 \%$ at lower frequency band compared to the size of the conventional patch antenna. Detailed theoretical and full wave analysis are presented and experimental results demonstrate a good agreement between the measured and the simulated. The suggested antennas can be employed for compact size and multiband functionalities in wireless applications. The loading technique can be adapted for more frequency bands.

\section{Introduction}

In wireless communication, the need for low profile antennas is a continuous demand for antenna engineer's community. Since different wireless applications are assigned differing frequencies, therefore, antennas are desirable to have multi band functionality. Moreover, these antennas are required to have an omnidirectional radiation pattern and simple design procedures. Many attempts for multiband antennas 
have been discussed in the literature. These attempts include using different radiating resonators which can be either separated on one/two sides of the printed antenna [1]-[4], or incorporated in one configuration [5],[6]. However, the first approach increases the antenna size; especially when the number of bands increases. Also, the second approach is difficult in design; especially when the number of desired operating bands increases.

The planar left handed metamaterials transmission line has been presented with promising electromagnetic wave properties for new trend in designing microwave components and antennas. It has been realized by loading a transmission line (TL) with series capacitors and shunt inductors known as a composite right / left handed (CRLH) [7] or negative refractive index [8]. CRLH TL has been employed in miniaturization of single/multiband functionalities for planar antennas [9]-[17].

To introduce even more compact size and multi-bands, different modifications based on increasing the order of the CRLH TL have been suggested. These approaches are dual CRLH TLs [18], inductor loaded CRLH TL [19], extended CRLH TL [20][22], generalized LHM TL [23]-[25], expanded CRLH TL [26] and doubled CRLH TL [27]. However, one of the drawbacks of these attempts is the increase of the complexity of the unit cell structure and hence the microwave element design procedures.

To simplify antenna design, antennas have made use of the idea of reducing CRLH unit cell by using only two elements in [28],[29]. However, detailed analyses of antenna designs were not provided. In this paper, we present detailed design procedures and analysis based on the concept of simplified half mode CRLH (H-CRLH) antennas [30]-[32]. Also, extensive full wave simulation and experimental measurements are presented to confirm the analysis. 


\section{Half Mode CRLH Inspired Antenna Principles}

Conventional CRLH unit cell is formed by loading a planar transmission line with series capacitor $\left(\mathrm{C}_{\mathrm{L}}\right)$ and shunt inductor $\left(\mathrm{L}_{\mathrm{L}}\right)$. The equivalent circuit of a lossless CRLH unit cell is shown in Fig. 1, where $C_{R}$ and $L_{R}$ are corresponding to the patristic elements of loaded transmission line. The basic concept of CRLH resonating antenna is to terminate the CRLH cell with either short or open circuit as shown in Fig. 1 (a). In the case of open circuit termination, the operating frequencies of CRLH TL based antennas is [9]

$$
\phi_{o c}=\left(\frac{1}{\omega \sqrt{C_{L} L_{L}}}-\omega \sqrt{C_{R} L_{R}}\right)= \pm n \pi, n=0,1, . .(N-1)
$$

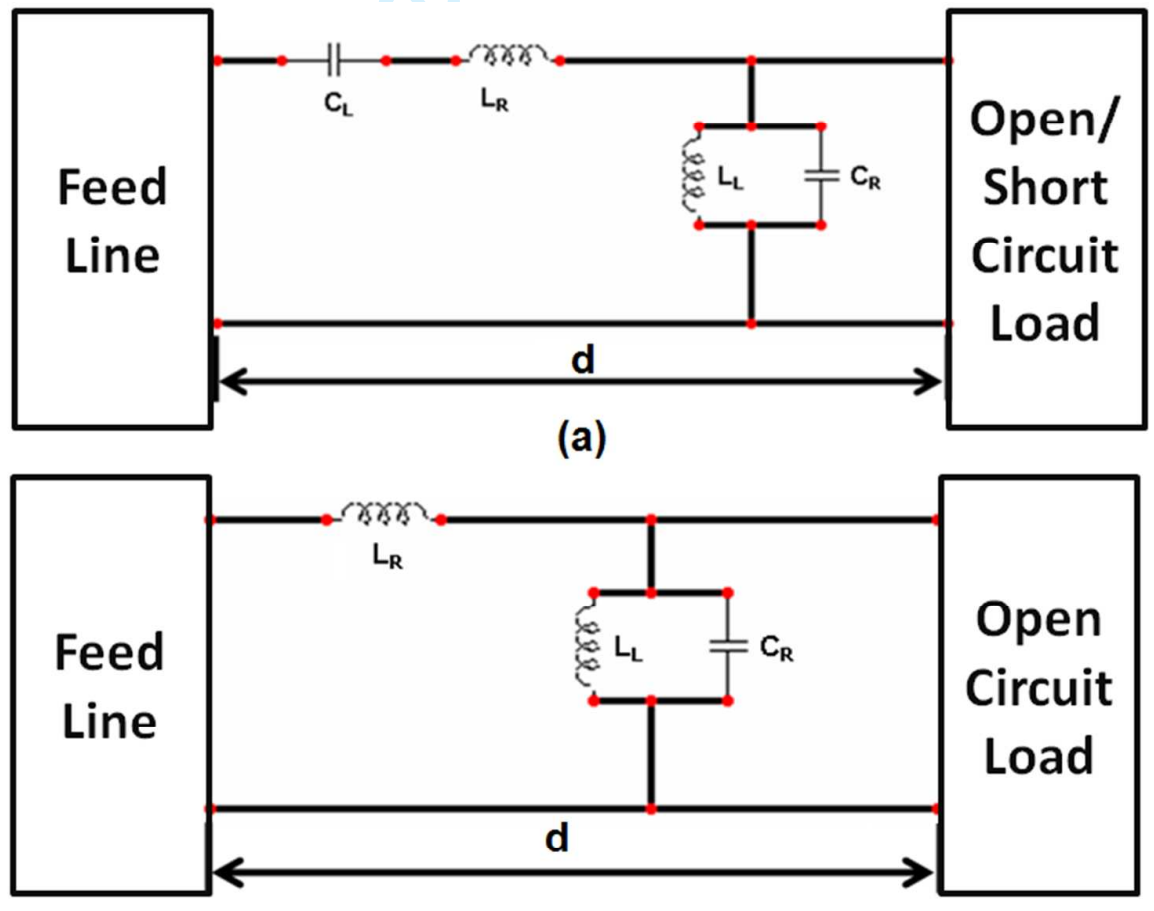

(b)

Fig. 1. The equivalent circuit model of the CRLH TL antenna (a) The full mode case (b) The practical half mode case.

Compact zeroth order antenna has been suggested in [7], however, it has been suggested in [31] that simpler and ultra compact metamaterial antenna is possible by using open- 
circuited terminated H-CRLH cell. The H-CRLH based antenna is shown in Fig. 1 (b), where it is realized by loading a TL with only shunt inductive load with no series capacitive load. The resonance frequency for the shunt branch $\left(f_{0 s h}\right)$ can be written as

$$
f_{0 s h}=\frac{1}{2 \pi \sqrt{L_{L} C_{R}}}
$$

\section{Dual Band H-CRLH Resonator Inspired Antenna}

\section{Dual Band Antenna Structure}

The dual band CPW antenna is fed by a $50 \Omega$ line (length $=12 \mathrm{~mm})$ on low loss Duroid substrate with $\varepsilon_{\mathrm{r}}=2.2$, and $1.59 \mathrm{~mm}$ thickness. The antenna is designed by loading a thin monopole antenna ( $\mathrm{T}$ shape) with narrow meander line to fulfil the equivalent circuit in Fig. 1 (b). The unloaded antenna layout is shown in Fig. 2 (a), where the antenna dimensions were specified to adjust the monopole resonance at 2.4 GHz with as small size as possible. The simulated reflection coefficient of the unloaded monopole antenna is shown in Fig. 4. As it can been seen, the antenna has a resonance with $-14 \mathrm{~dB}$ reflection coefficient at $2.4 \mathrm{GHz}$.

The dual band H-CRLH inspired antenna geometry is shown in Fig. 2 (b). The antenna is constructed by loading the previously designed $\mathrm{T}$ shaped monopole with multi turns meander line. The narrow gaps in the meander line should be equivalent to a capacitor $\left(C_{R}\right)$ connected in parallel with the line inductance $\left(L_{L}\right)$. Comparing this configuration to H-CRLH antenna in Fig. 1 (b), we can notice that this configuration makes use only of the shunt parallel tank circuit with no complete transmission line realization. The dimensions for the T-Shape strip monopole and the overall antenna size are the same as those in Fig. 2 (a). The dimensions of the employed meander line were adjusted for introducing a second band at $5.8 \mathrm{GHz}$ using (2). The fabricated dual band half mode antenna prototype is shown in Fig. 3. 


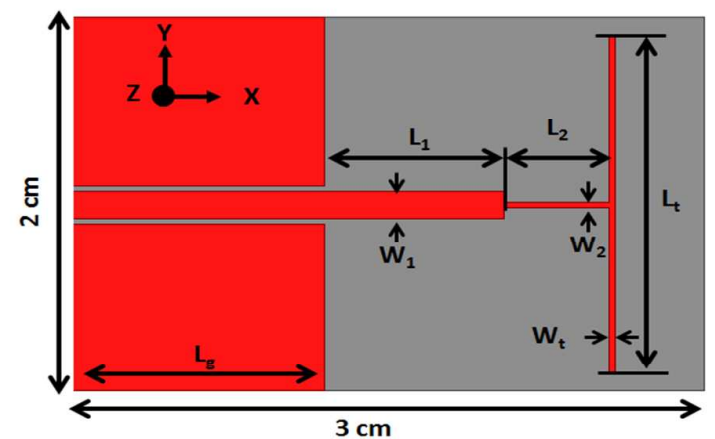

(a)

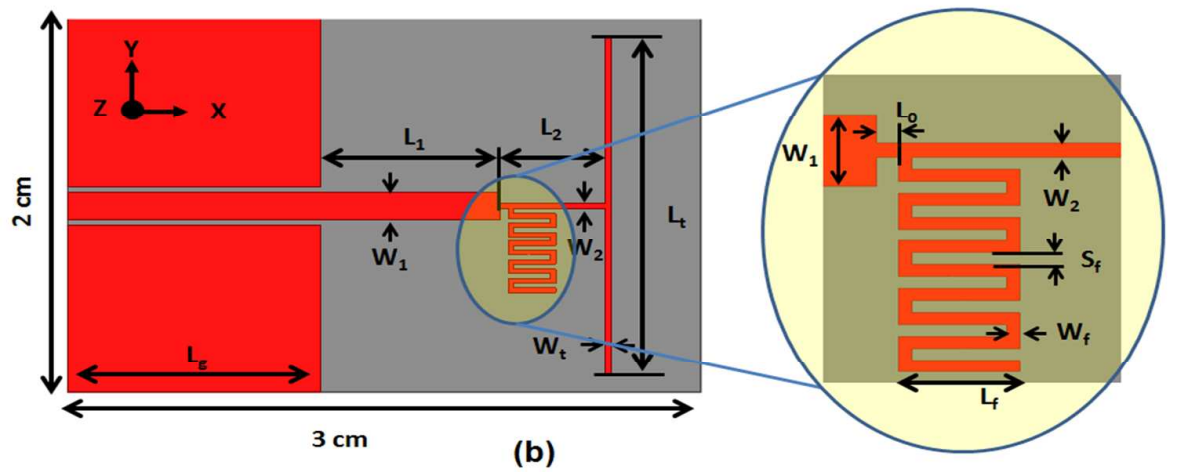

Fig. 2. The dual band H-CRLH inspired antenna (a) The unloaded antenna $\left(\mathrm{W}_{1}=1.5 \mathrm{~mm}\right.$ and $\mathrm{W}_{2}=\mathrm{W}_{\mathrm{t}}=0.3 \mathrm{~mm}, \mathrm{~L}_{1}=8.5, \mathrm{~L}_{2}=5 \mathrm{~mm}$ and $\left.\mathrm{L}_{\mathrm{t}}=18 \mathrm{~mm}\right)(\mathrm{b})$ the loaded antenna $\left(\mathrm{L}_{0}=0.4 \mathrm{~mm}\right.$, $\left.\mathrm{L}_{\mathrm{f}}=2.25 \mathrm{~mm}, \mathrm{~W}_{\mathrm{f}}=\mathrm{S}_{\mathrm{f}}=0.25 \mathrm{~mm}\right)$

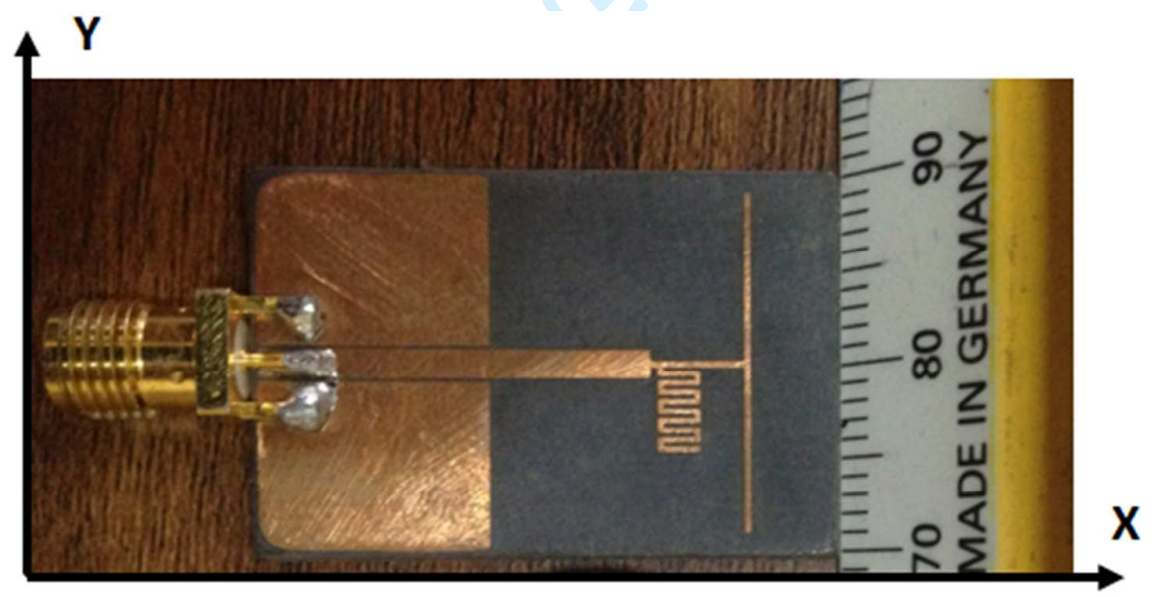

Fig. 3. The fabricated dual band H-CRLH inspired antenna prototype.

Both full wave simulation and experimental measurement results are shown in Fig. 4, a good agreement between the two can be observed. As shown, the antenna can demonstrate almost identical and better than $-15 \mathrm{~dB}$ in the reflection coefficient at the two designed frequencies. Comparing the results of the unloaded and loaded antennas, 
we can observe that the first band at $2.4 \mathrm{GHz}$ is the same with or without using loading cell. Also, it is observed that the antenna has better than $10 \mathrm{~dB}$ bandwidth from $2 \mathrm{GHz}$ 2.8 GHz in the first $2.4 \mathrm{GHz}$ band and $5.74 \mathrm{GHz}-5.95 \mathrm{GHz}$ in the second band.

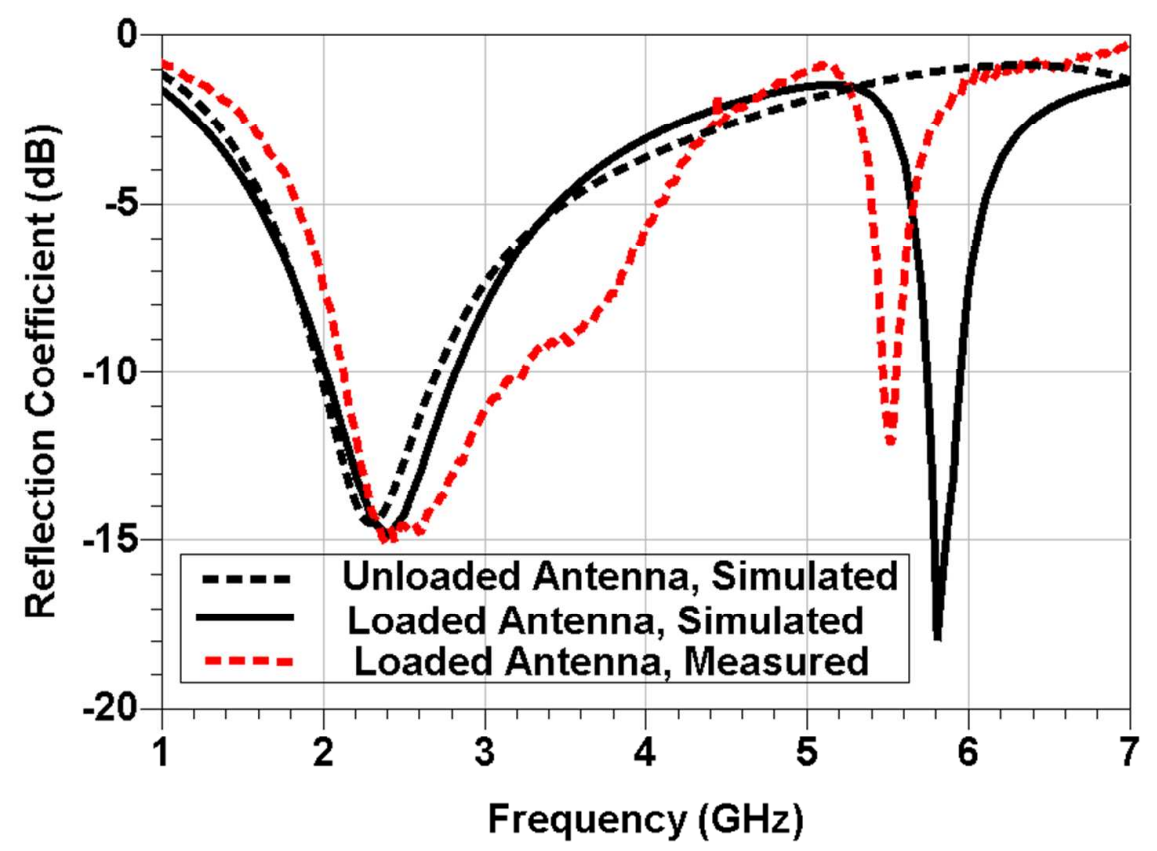

Fig. 4. The comparison between the simulated reflection coefficient for the loaded / unloaded antennas and the measured one for the loaded dual band antenna.

\section{Dual Band Antenna Radiation Mechanism}

To confirm the radiation mechanism of the dual band antenna, the simulated current distribution at $2.4 \mathrm{GHz}$ and $5.8 \mathrm{GHz}$ were extracted and plotted in Fig. 5. It can be seen that at $2.4 \mathrm{GHz}$, peak current is concentrated along the thin strip monopole with weak current passing through the loading meander line. This can be explained that the resonance is caused by the unloaded monopole. However, at $5.8 \mathrm{GHz}$, the peak current is passing through the loading meander line. The current distribution results confirm that the radiation mechanism of the second band is due to the resonance introduced by the meander line resonator.

The role of the loading meander line can be further confirmed by simulating the antenna for different values of the finger length $\left(\mathrm{L}_{\mathrm{f}}\right)$, as shown in Fig. 6. It is obvious 
that the change of the finger length does not affect the first band at $2.4 \mathrm{GHz}$. However, by increasing the finger length, i.e., increasing both $L_{L}$ and $C_{R}$ the resonant frequency is shifted down to $5.2 \mathrm{GHz}, 5.6 \mathrm{GHz} 6.1 \mathrm{GHz}$ and $6.9 \mathrm{GHz}$ for $\mathrm{L}_{\mathrm{f}}=2.5 \mathrm{~mm}, 2 \mathrm{~mm}, 1.5$ $\mathrm{mm}$ and $1 \mathrm{~mm}$, respectively. This result can also confirm the resonance behaviour in (2) that supports our loading principles.

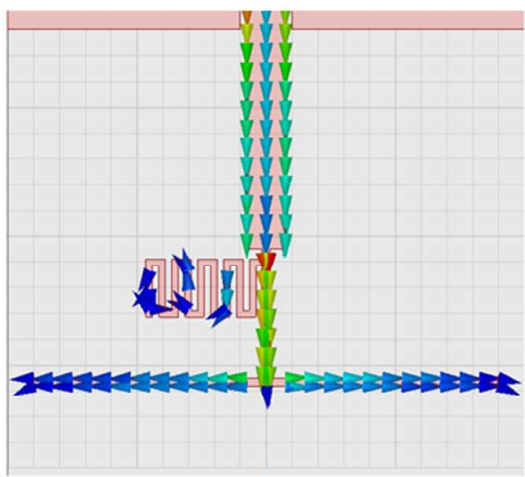

(a)

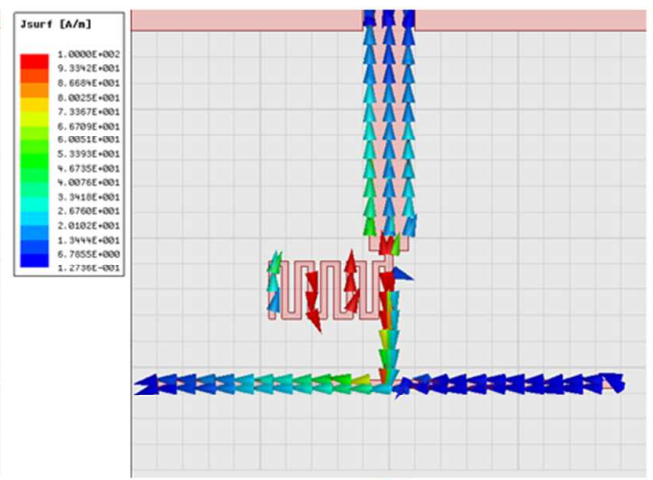

(b)

Fig. 5. The current distribution of the dual band inspired H-CRLH antenna at (a) $2.4 \mathrm{GHz}$, (b) 5.8 GHz.

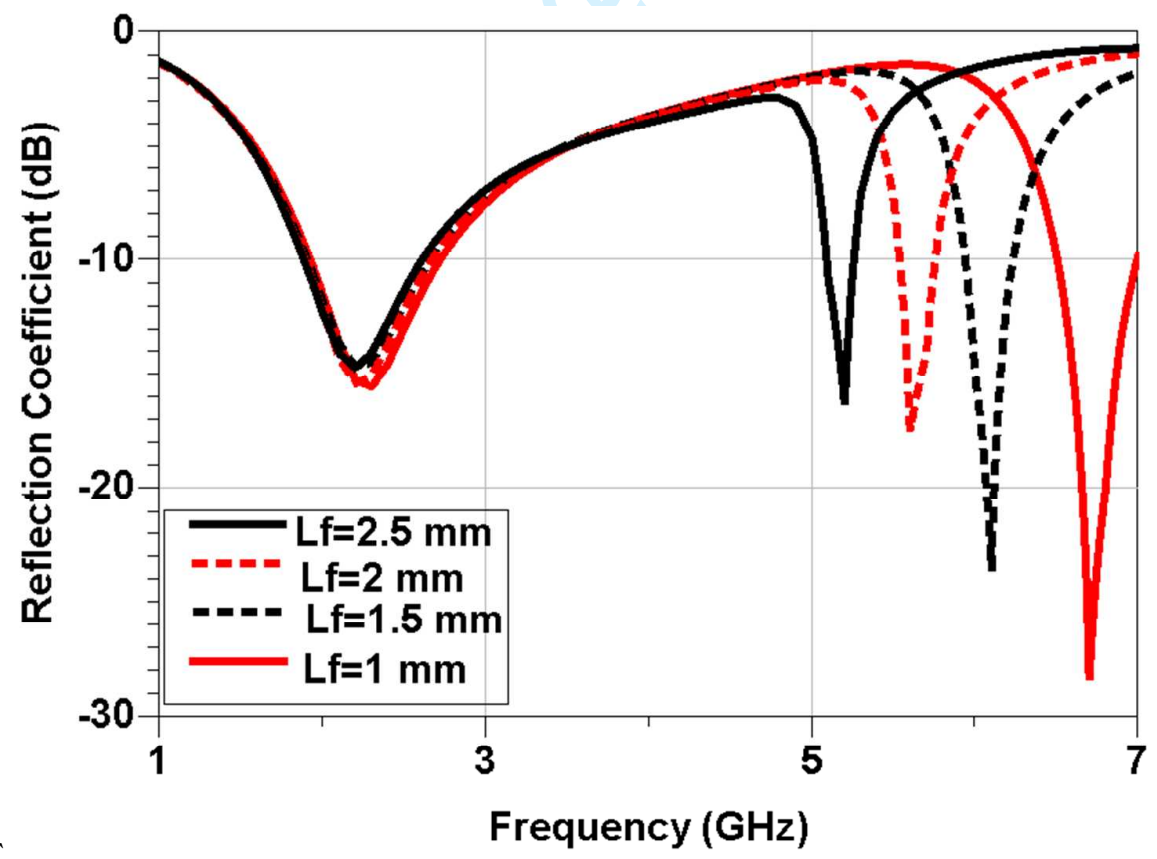

Fig. 6. The simulated reflection coefficient of the dual band H-CRLH inspired antenna for different $\mathrm{L}_{\mathrm{f}}$ values. 


\section{The Antenna Radiation Properties}

The antenna radiation performance at the two operating band has been checked by investigating the radiation pattern at each band centre frequency. The $3 \mathrm{D}$ normalized power pattern at $2.4 \mathrm{GHz}$ and $5.8 \mathrm{GHz}$ of the dual band antenna is shown in Fig. 7. It is obvious that the dual band antenna has an omni-directional radiation pattern with maximum radiation in $\mathrm{Z}$ direction, perpendicular to the antenna. Such radiation pattern is appreciated in the WiMAX applications for which the antenna was designed.

The antenna gain, directivity and radiation efficiency were computed at the two operating frequencies as summarized as in Table 1. It can be high-lighted that excellent efficiency was achieved which makes the antenna very good for wireless services.

Table I: The dual band antenna radiation parameters summary

\begin{tabular}{|l|l|l|}
\hline Antenna Parameter & Frequency $(2.4 \mathrm{GHz})$ & Frequency $(5.8 \mathrm{GHz})$ \\
\hline Antenna Directivity & $2.39 \mathrm{~dB}$ & $3.41 \mathrm{~dB}$ \\
\hline Antenna Efficiency & $-0.04 \mathrm{~dB}(99 \%)$ & $-0.06 \mathrm{~dB}(98 \%)$ \\
\hline Antenna Gain & $2.35 \mathrm{~dB}$ & $3.35 \mathrm{~dB}$ \\
\hline
\end{tabular}

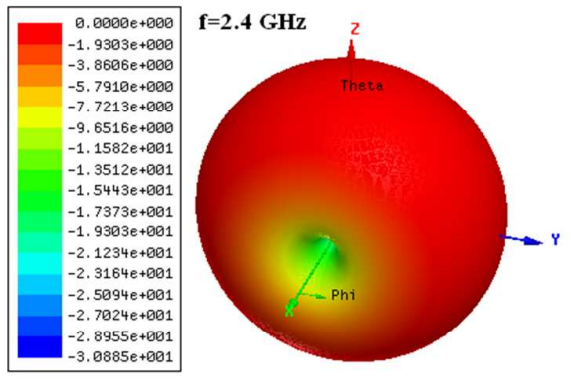

(a)

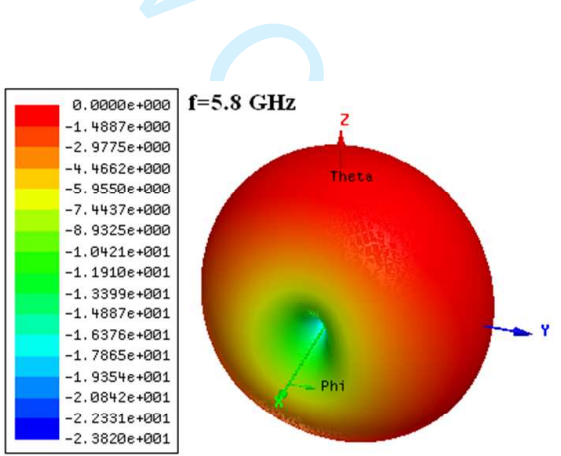

(b)

Fig. 7. The 3D normalized radiation pattern at $2.4 \mathrm{GHz}$ and $5.8 \mathrm{GHz}$ of the dual band $\mathrm{H}-\mathrm{CRLH}$ inspired antenna.

A comparison between the measured and simulated radiation pattern in the $\mathrm{H}$ plane (YZ plane) and E plane (XZ plane) at $2.4 \mathrm{GHz}$ and $5.8 \mathrm{GHz}$ are shown in Fig. 8 
and Fig. 9, respectively. It is clear that there is a very good between the two data in both planes at $2.4 \mathrm{GHz}$ whereas within the $\mathrm{H}$ plane, the plane is isotropic pattern and it is typical figure of eight. On the other hand, at $5.8 \mathrm{GHz}$, in Fig. 9, the comparison illustrates the same phenomenon with slight variation in the E plane at $\theta=120^{\circ}$. Both of the results given in Fig. 8 and Fig. 9 confirm the simulated 3D pattern. The data in Fig. 8, agrees with the data in Fig. 7.

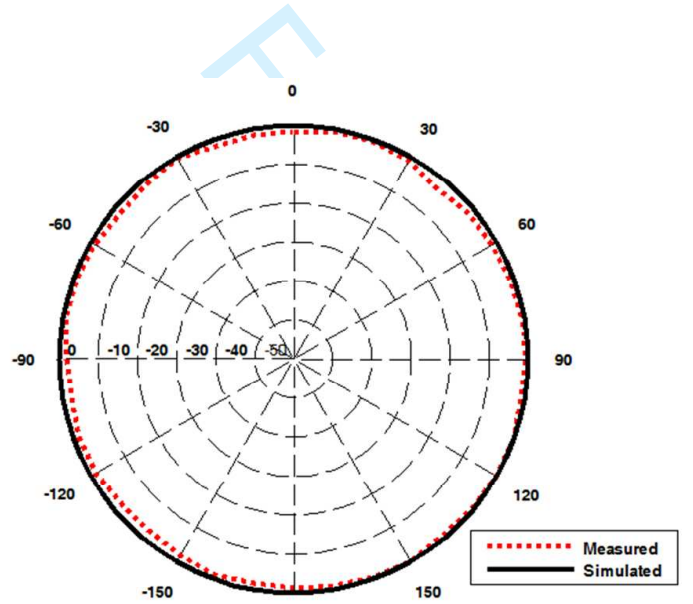

180

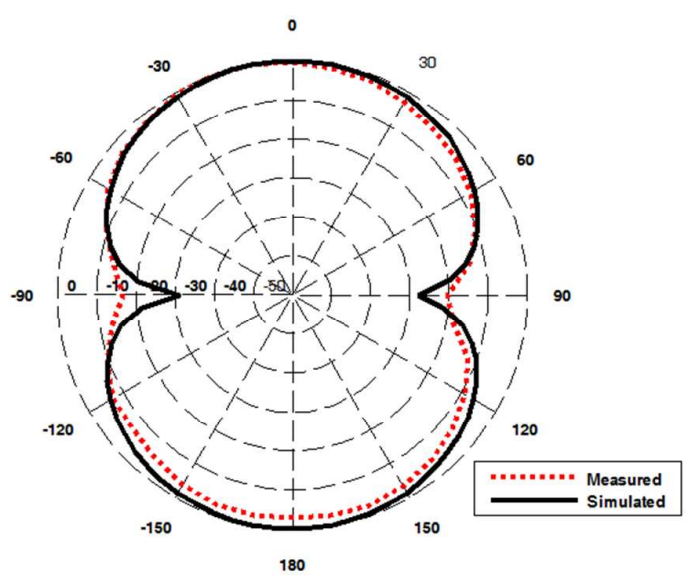

(b)

Fig. 8. A comparison between the simulated and measured radiation pattern of the the dual band $\mathrm{H}-\mathrm{CRLH}$ inspired antenna at $2.4 \mathrm{GHz}$ in (a) $\mathrm{H}$ (YZ) plane, (b) E (XZ) plane

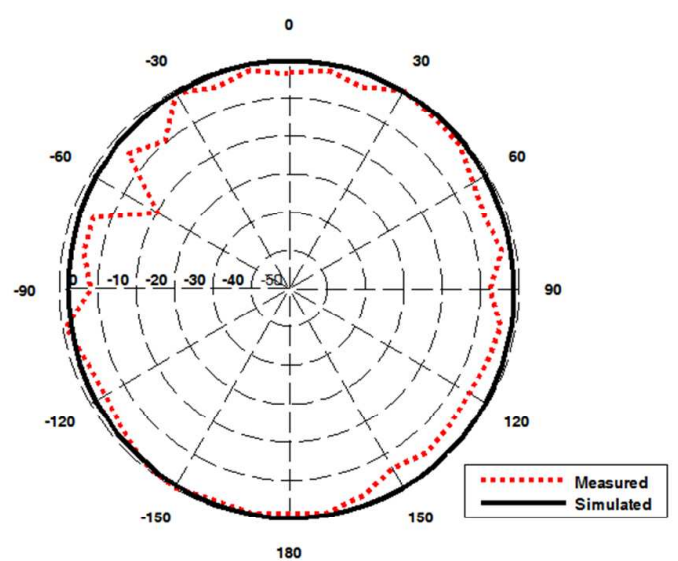

(a)

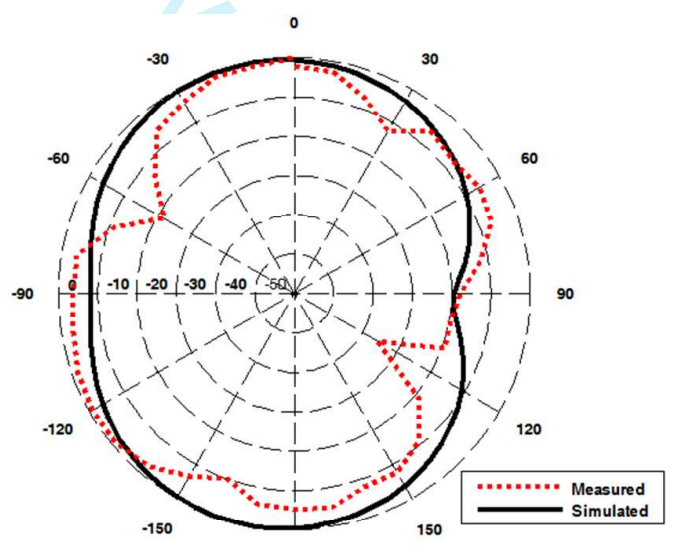

(b)

Fig. 9. A comparison between the simulated and measured radiation pattern of the dual band HCRLH inspired antenna at $5.8 \mathrm{GHz}$ in (a) $\mathrm{H}$ (YZ) plane, (b) E (XZ) plane 


\section{Triple Band Asymmetric H-CRLH Resonator Inspired Antenna}

\section{Triple Band Antenna Structure}

The triple band antenna configuration is shown in Fig. 10 (a) and the fabricated antenna prototype is shown in Fig. 10 (b). As shown, the antenna geometry is based on loading a thin monopole with two different tank circuits (tank circuit \# 1 corresponding to $\mathrm{L}_{\mathrm{L} 1}$ and $\mathrm{C}_{\mathrm{R} 1}$ in one side and tank circuit \# 2 corresponding to $\mathrm{L}_{\mathrm{L} 2}$ and $\mathrm{C}_{\mathrm{R} 2}$ on the second side). The antenna is fed by a $50 \Omega$ microstrip line. The antenna is fabricated on low cost FR 4 substrate with dielectric constant $=4.3$, thickness $=1.6 \mathrm{~mm}$, and $\tan \delta=0.02$. The two different resonator circuits are formed using two different meander lines in length and number of lines. All the meander line space and width were $0.25 \mathrm{~mm}$.

The triple bands are the result of the resonance of each shunt resonator circuit. The tank circuit \# 1 is constructed using longer meander line ( 9 pairs of $\mathrm{L}_{\mathrm{f} 1}=2.6 \mathrm{~mm}$ ) whereas tank circuit \# 2 is constructed using only pair of $L_{f 2}=2 \mathrm{~mm}$ ). Therefore, $L_{L 1}$ and $C_{R 1}$ will be larger than $\mathrm{L}_{\mathrm{L} 2}$ and $\mathrm{C}_{\mathrm{R} 2}$. As a consequence, the antenna has two resonance frequencies, $\mathrm{f}_{1}$ and $\mathrm{f}_{2}$. In addition a third resonance, $\mathrm{f}_{3}$, can be obtained due to the overall resonance of the two tank circuits.

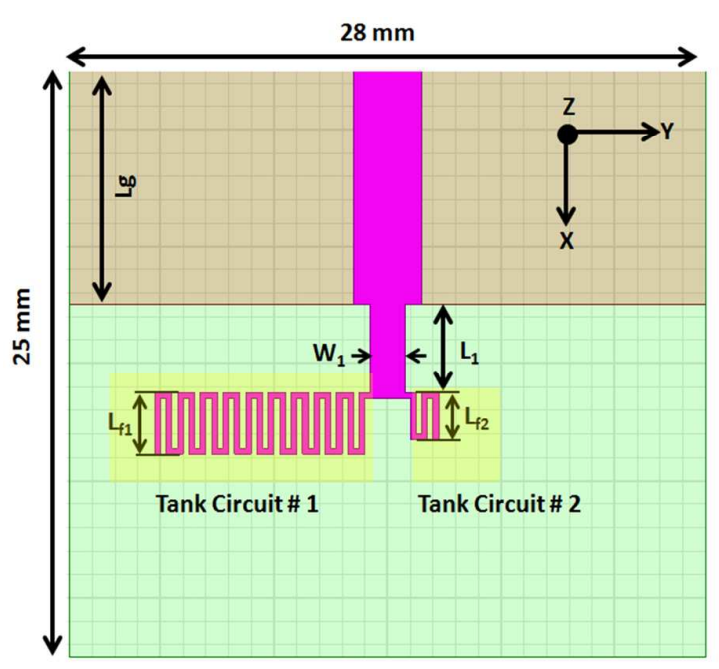

(a)

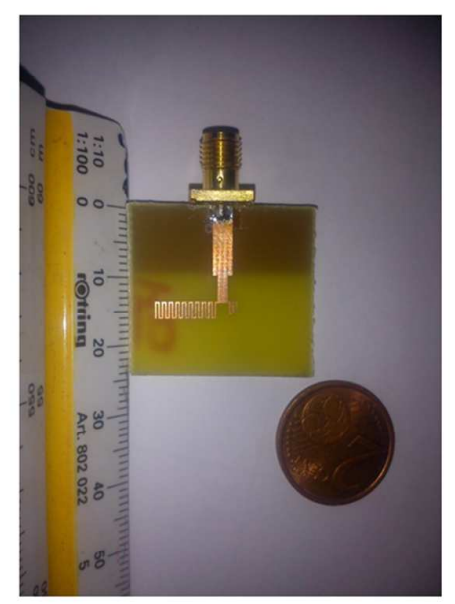

(b)

Fig. 10. The H-CRLH inspired triple band antenna layout $\left(\mathrm{L}_{\mathrm{g}}=10 \mathrm{~mm}, \mathrm{~L}_{1}=3.75 \mathrm{~mm}, \mathrm{~W}_{1}=1.5\right.$ $\mathrm{mm}, \mathrm{L}_{\mathrm{f} 1}=2.6 \mathrm{~mm}$ and $\mathrm{L}_{\mathrm{f} 2}=2 \mathrm{~mm}$,) (b) The fabricated prototype antenna 
The antenna design was examined using the electromagnetic full wave simulation and experimental measurement as shown in Fig. 11. As shown it can be seen, the antenna can demonstrate triple band. The first band is centred at $2.2 \mathrm{GHz}$ with lower than -10 $\mathrm{dB}$ reflection coefficient bandwidth from $2 \mathrm{GHz}-2.4 \mathrm{GHz}$. The second band is centred at $5.7 \mathrm{GHz}$ with bandwidth from $5.4 \mathrm{GHz}-6 \mathrm{GHz}$. The third band is centred at $7.3 \mathrm{GHz}$ with bandwidth from $6.8 \mathrm{GHz}-8 \mathrm{GHz}$. The reflection coefficients at the centre frequency of the three bands are all better than $-10 \mathrm{~dB}$. Good agreement between the simulated and measured results are also achieved.

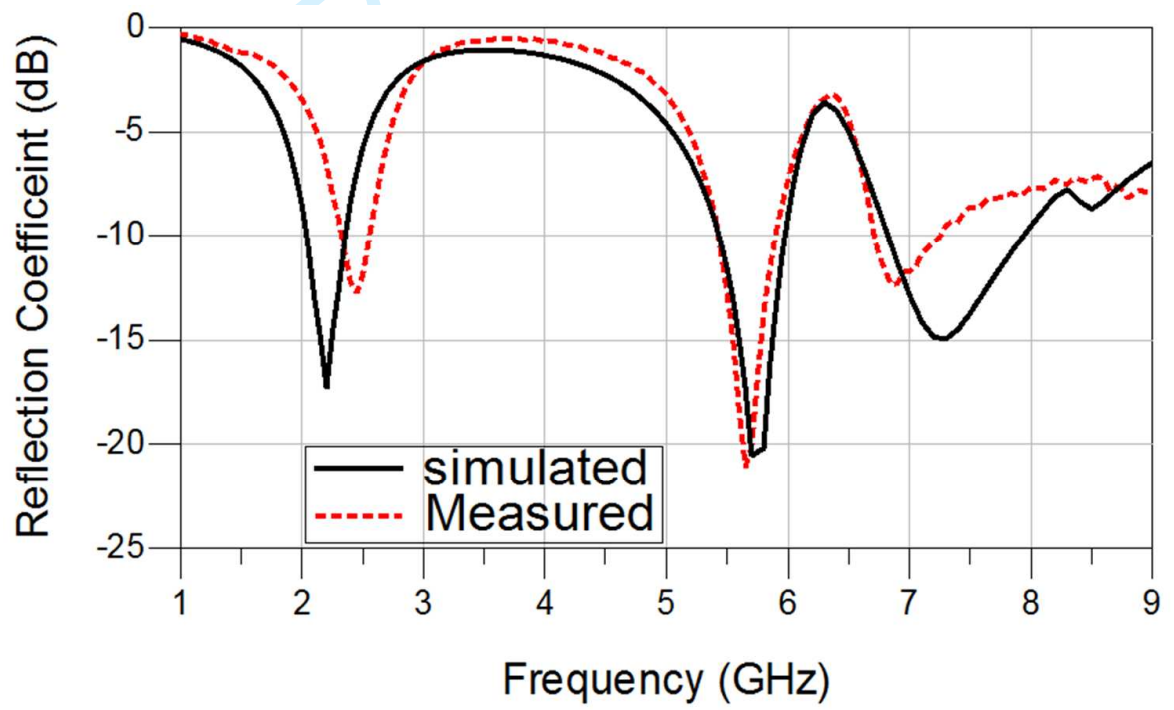

Fig. 11. The simulated and measured results of the triple band H-CRLH triple band antenna.

Triple Band Antenna Radiation Mechanism

A confirmation of the radiation mechanism can be done by plotting the current distribution at the three resonance frequencies $2.2 \mathrm{GHz}, 5.7 \mathrm{GHz}$ and $7.3 \mathrm{GHz}$ in Fig. 12 (a), (b) and (c), respectively. As shown in Fig. 12 (a), the current is concentrated at resonator \# 1 which agrees with the theoretical prediction. In Fig. 12 (c), the current is concentrated at the resonator \# 2 which also confirms the theoretical prediction. In Fig. 12 (b), at $5.7 \mathrm{GHz}$, the current is concentrated at the two resonators which can be claimed that the resonance is due the contribution of overall resonances. 

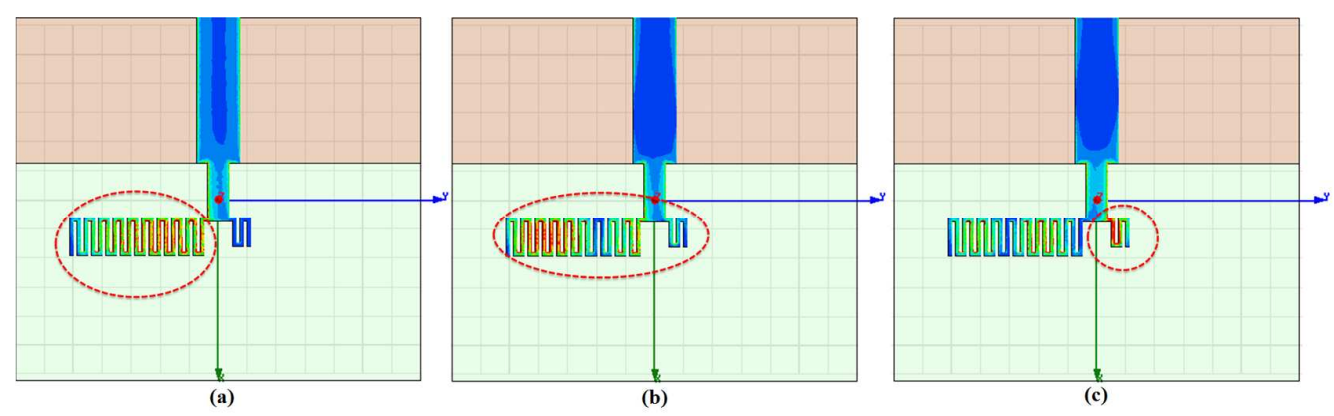

Fig. 12 The simulated current distribution along the triple band H-CRLH inspired antenna at (a) $2.2 \mathrm{GHz}$, (b) $5.7 \mathrm{GHz}$ and (c) $7.3 \mathrm{GHz}$.

\section{Triple Bands Antenna Radiation Properties}

The 3D radiation patterns at the three centre frequencies are shown in Fig. 13. As shown, the three patterns are almost omnidirectional. The pattern at $2.2 \mathrm{GHz}$ is the most typical omnidirectional one whereas that at $7.3 \mathrm{GHz}$ is less typical one. This point can be emphasized by (1) effect of difference between measured and simulated reflection coefficient at $7.3 \mathrm{GHz}$ in Fig. 11. (2) Also, this can be conducted as some difference in measured and simulated antenna gain at $5.7 \mathrm{GHz}$ and $7.3 \mathrm{GHz}$.

Similar to dual band antenna, the triple band antenna gain, directivity and radiation efficiency were computed at the two operating frequencies as summarized as in Table II.

Table II: The triple band antenna radiation parameters summary

\begin{tabular}{|l|l|l|l|}
\hline Antenna Parameter & Freq. (2.2 GHz) & Freq. (5.7 GHz) & Freq. (7.3 GHz) \\
\hline Antenna Directivity & $2.2 \mathrm{~dB}$ & $3.39 \mathrm{~dB}$ & $4.36 \mathrm{~dB}$ \\
\hline Antenna Efficiency & $-2.6 \mathrm{~dB}(55 \%)$ & $-0.49 \mathrm{~dB}(89 \%)$ & $-0.41 \mathrm{~dB}(88 \%)$ \\
\hline Antenna Gain & $-0.04 \mathrm{~dB}$ & $2.9 \mathrm{~dB}$ & $3.95 \mathrm{~dB}$ \\
\hline
\end{tabular}

Similar to the dual band antenna, the presented data confirm that the antenna is a good candidate for wireless applications. It is wort to comment that the triple band has 
relatively lower values, compared to dual band antenna, as the triple one was implemented on low cost lossy FR4 substrate.

Similar to verification has been done for the dual band antenna, a comparison between measured and simulated radiation patterns of the triple band H-CRLH inspired antenna in the $\mathrm{H}$ plane and E plane at 2.2 GHz, 5.7 GHz and 7.3 GHz are shown in Fig. 14, Fig. 15 and Fig. 16, respectively. Relatively good agreement between the measured and simulated can be observed.
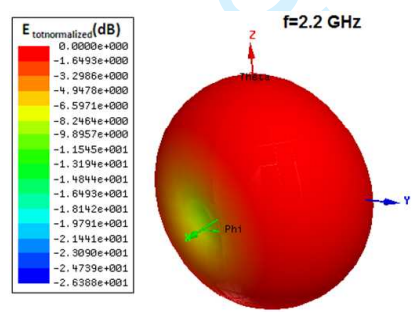

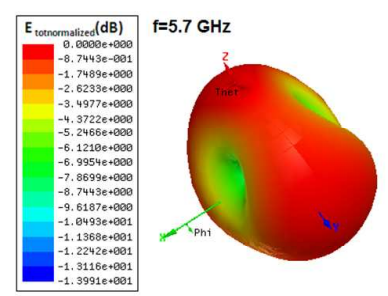

(b)

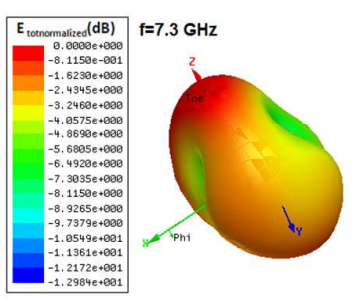

(c)

Fig. 13. The simulated $3 \mathrm{D}$ radiation pattern at $2.2 \mathrm{GHz}, 5.7 \mathrm{GHz}$, and $7.3 \mathrm{GHz}$ of the triple band H-CRLH inspired antenna.

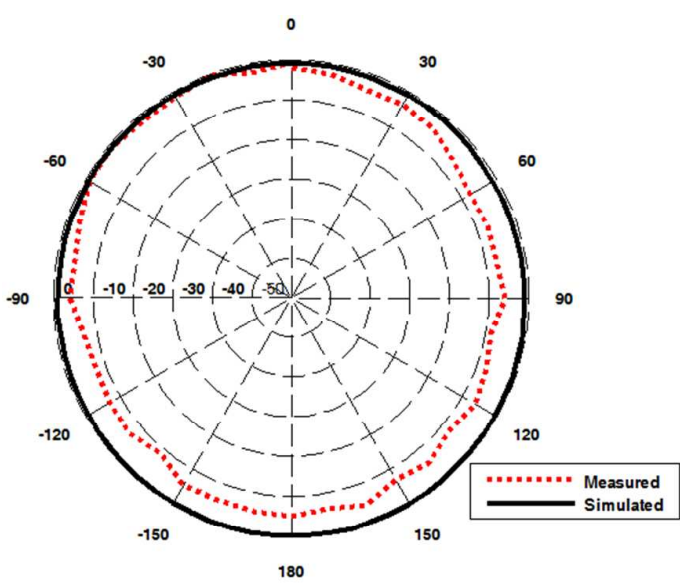

(a)

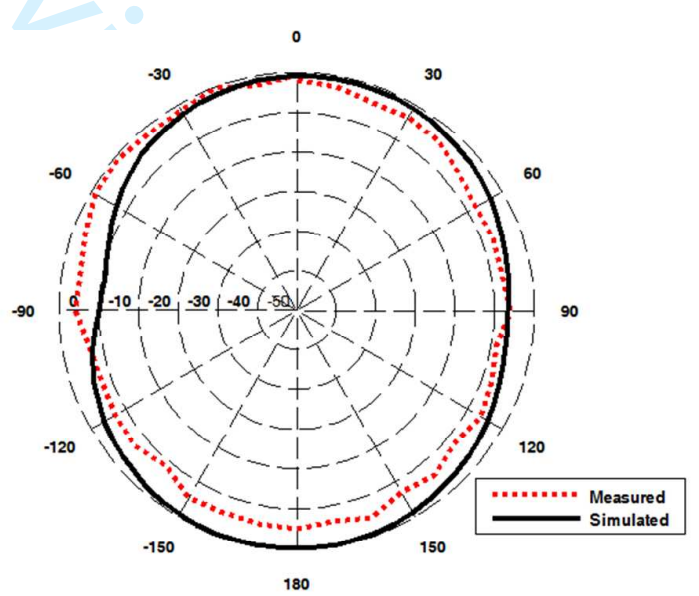

(b)

Fig. 14. A comparison between the simulated and measured radiation pattern of the H-CRLH inspired triple band antenna at $2.2 \mathrm{GHz}$ in (a) $\mathrm{H}(\mathrm{YZ})$ plane, (b) E (XZ) plane 


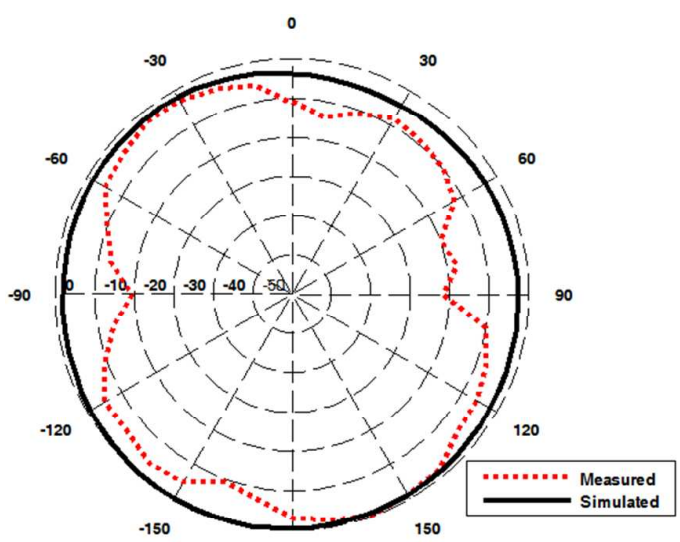

180

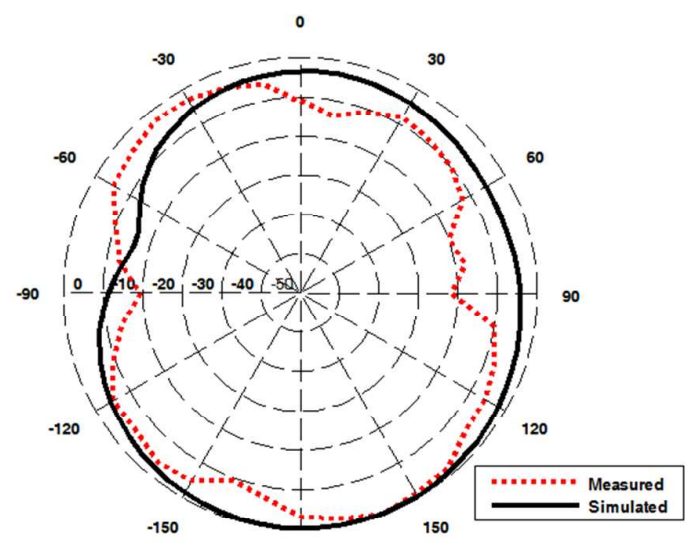

180

Fig. 15. A comparison between the simulated and measured radiation pattern of the H-CRLH inspired triple band antenna at $5.7 \mathrm{GHz}$ in (a) $\mathrm{H}$ (YZ) plane, (b) E (XZ) plane

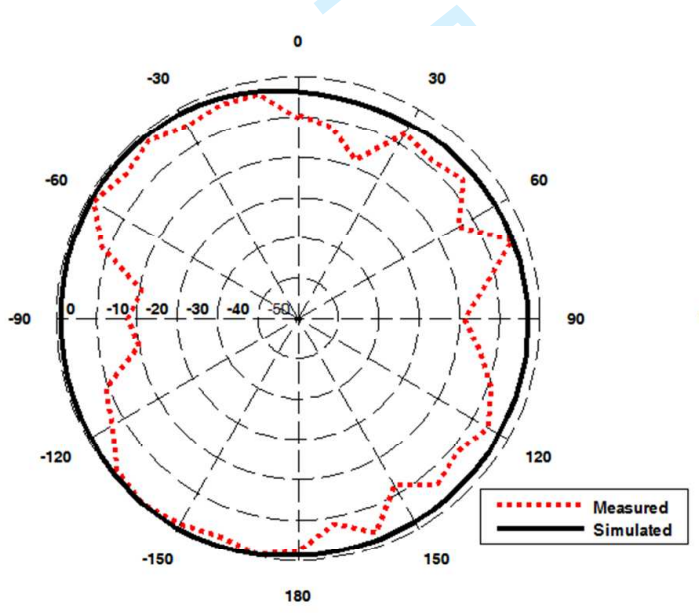

(a)

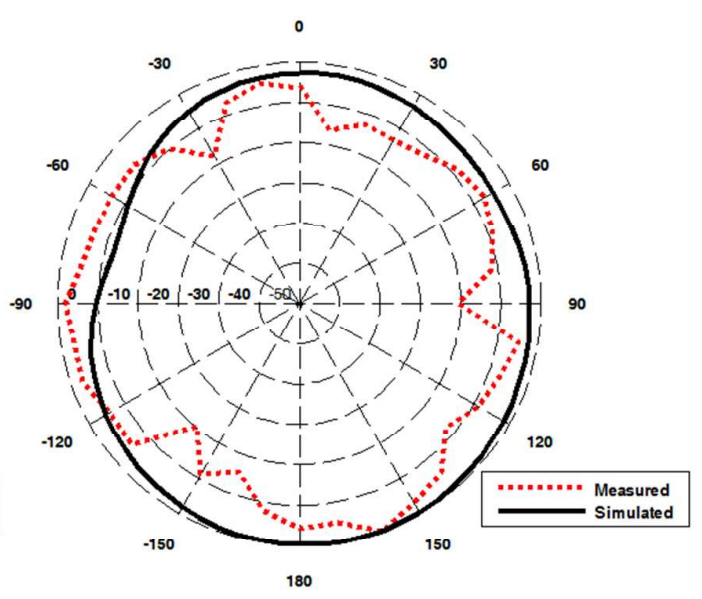

(b)

Fig. 16. A comparison between the simulated and measured radiation pattern of the H-CRLH inspired triple band antenna at $7.3 \mathrm{GHz}$ in (a) $\mathrm{H}(\mathrm{YZ})$ plane, (b) $\mathrm{E}(\mathrm{XZ})$ plane

\section{Conclusion}

A detailed study of new configurations for dual/triple bands H-CRLH inspired antennas are presented. The study has been emphasized using the full wave simulation and experimental results. The first antenna is a compact dual band antenna for lower 2.4 $\mathrm{GHz}$ and upper 5.8 GHz WiMAX frequency bands with almost typical omni-directional radiation pattern at the two operating frequencies. The antenna size is only $30 \times 20 \mathrm{~mm}^{2}$ where the antenna has been miniaturized up to $75 \%$ compared to conventional patch antenna. The second antenna is a triple band antenna at $2.2 \mathrm{GHz}, 5.7 \mathrm{GHz}$ and $7.3 \mathrm{GHz}$ 
of an omnidirectional pattern with minimum $15 \mathrm{~dB}$ return loss at the band canter frequency. The antenna is compact whose size is only $28 \times 25 \mathrm{~mm}^{2}$.

\section{References}

1. C. Deng, X. L. Liu, Z. Zhang, M.M. Tentzeris "A Miniascape-Like Triple-Band Monopole Antenna for WBAN Applications", IEEE Antennas and Wireless Propagation Letters, vol. 11, 2012, pp. 1330 - 1333

2. W. Liu, C. Wu, Y. Dai "Design of Triple-Frequency Microstrip-Fed Monopole Antenna Using Defected Ground Structure", IEEE Transactions on Antennas and Propagation, vol. 59, no. 7, 2011 , pp. 2457 - 2463.

3. T. Chang, Jean-Fu Kiang, "Compact Multi-Band H-Shaped Slot Antenna", IEEE Transactions on Antennas and Propagation, vol. 61, no. 8, 2013, pp. 4345 - 4349.

4. N. M. and T. A. Denidni, "A New Triple-Band Circular Ring Patch Antenna With Monopole-Like Radiation Pattern Using a Hybrid Technique", IEEE Transactions on Antennas and Propagation, vol. 59, no. 10, 2011, pp. 3512-3517.

5. X. L. Sun, J. Zhang, S. W. Cheung, T. I. Yuk "A triple-band monopole antenna for WLAN and WiMAX applications", 2012 IEEE Antennas and Propagation Society Int. Symposium (APSURSI), USA, pp. 1-2.

6. P. Moeikham, C. Mahatthanajatuphat, P. Akkaraekthalin "A triple band printed monopole antenna for WLAN/WiMAX applications", 2012 Int. Symposium on Antennas and Propagation (ISAP), Japan, pp. 295 - 298.

7. C. Caloz and T. Itoh, Electromagnetic Metamaterials Transmission Line Theory and Microwave Applications. New Jersey: John Wiey \& Sons, 2006.

8. G. V. Eleftheriades and K. G. Balmain, Negative Refractive Metamaterials. New Jersey: John Wiey \& Sons, 2005.

9. W. H. Lee, A. Gummalla, M. Achour, "Small Antennas Based on CRLH Structures: Concept, Design, and Applications", IEEE Ant. and Prop. Mag., vol. 53, no. 2, 2011, pp. 10-25.

10. R. W. Ziolkowski, P. Jin, C. Lin, "Metamaterial-Inspired Engineering of Antennas", IEEE Proceedings, vol. 99, no. 10, 2011, pp. 1720-1731.

11. Y. Dong, T. Itoh, "Metamaterial-Based Antennas", IEEE Proceedings, vol. 100, no. 7, 2012, pp. 2271-2285.

12. T. Jang, S. Lim, and T. Itoh. "Tunable compact asymmetric coplanar waveguide zerothorder resonant antenna." Journal of Electromagnetic Waves and Applications vol. 25, no. 17-18, 2011, pp. 2379-2388. 
1

2

3

4

5

6

7

8

9

10

13. Z. Li, F. Li, J. H. Wang, M. E. Chen, and Z. Zhang. "A novel compact MIM CRLH transmission line and its application to leaky-wave antenna." Journal of Electromagnetic Waves and Applications, vol. 25, no. 14-15, 2011, pp. 1999-2010.

14. J. Zhu, M. A. Antoniades, and G. V. Eleftheriades, "A compact tri-band monopole antenna with single-cell metamaterial loading" IEEE Trans. Antennas Propag., Vol. 58, 1031-1038, Apr. 2010.

15. P. Jin, C. C. Lin, and R. W. Ziolkowski, "Multifunctional, electrically small, planar near-field resonant parasitic antennas," IEEE Antennas Wireless Propag. Lett., vol. 11, 200-204, 2012.

16. T. Li, G. Wang, G. Wu, R. Tan, L. Geng, and H. Li. "Compact wideband antenna based on novel composite right/left handed transmission line." Journal of Electromagnetic Waves and Applications vol. 29, no. 9 2015, pp. 1140-1148.

17. M. Barbuto, F. Trotta, F. Bilotti, and A. Toscano, "Design of a low-profile antenna by using orthogonal parasitic meandered monopoles," Progress In Electromagnetics Research Letters, Vol. 55, pp. 23-29, 2015.

18. C. Caloz, ”Dual Composite Right/Left-Handed (D-CRLH) Transmission Line Metamaterial, ’IEEE Microwave and Wireless Components Letters, vol. 16, no. 11, 2006, pp. 585-587.

19. A. F. Daw, Mahmoud Abdalla, Hadia M. Elhennawy, "New Inductor Loaded Composite Right Left hand Impedance Transformer for UWB Wireless Applications", 2015 9th International Congress on Advanced Electromagnetic Material in Microwave and Optics, September 2015, UK, pp. 231-233

20. A Rennings, K. L. Kamp-Lintfort, S. Otto, J. Mosig, C. Caloz, "Extended composite right/left-handed (E-CRLH) metamaterial and its application as quadband quarterwavelength transmission line", APMC 2006. Asia-Pacific Microwave Conference, pp. 1405-1408.

21. M. Durán-Sindreu, J. Bonache, F. Martín and T. Itoh, "Novel Fully-Planar ExtendedComposite Right/Left Handed Transmission Line based on Substrate Integrated Waveguide for Multi-Band Applications", in proceedings of the 42nd European Microwave Conference, EuMC, 2012 Netherlands, pp. 578-581.

22. L. Qiang and H.-M. Lu, W. Zhao and J.-K. Wang, B. Liu, "Simplified extended composite right/left handed transmission line structure for dual band applications", Progress In Electromagnetics Research Letters, vol. 15, 2010, pp. 137-144.

23. G. V. Eleftheriades, 'A generalized negative-refractive-index transmission-line (NRITL) metamaterial for dual-band and quad-band applications'. IEEE Microw. Wireless Compon. Lett. vol. 17, no. 6, 2007, pp. 415-417. 
24. C. Ryan, and G. Eleftheriades, "Design of a printed dual-band coupled-line coupler with generalised negative-refractive index transmission lines". IET microwaves, antennas \& propagation, vol. 6, 2012, pp. 705-712.

25. M. A. Fouad and M. A Abdalla, "A New $\pi$-T Generalized Metamaterial NRI Transmission Line for a Compact CPW Triple BPF Applications", IET microwave, antenna and propagation, vol. 8, no. 9, 2014, pp. 1097-1104.

26. M. Selvanayagam and G. V. Eleftheriades, "Negative-Refractive-Index Transmission Lines With Expanded Unit Cells", IEEE Transaction on antennas and propagation, vol. 56, no. 11, 2008, pp. 3592-3596.

27. C. Jin, A. Alphones and M. Tsutsumi, "Double Periodic Composite Right/Left Handed Transmission Line and Its Applications to Compact Leaky-Wave Antennas", IEEE Transaction on Antennas and Propagation, vol. 59, no. 10, 2011, pp. 3679-3686.

28. M. A. Abdalla and Z. Hu "A compact Dual Band Meta-material Antenna for Wireless Applications", 2012 Loughborough Antennas \& Propagation Conference, Loughborough, UK, 1-4, 2012.

29. M. Abdalla, M. Fouad A. Ahmed and Z. Hu, "A New Compact Microstrip Triple Band Antenna Using Half Mode CRLH Transmission Line" 2013 IEEE AP-S International Antenna and Propagation Symposium Digest, Orlando, USA, 634-635.

30. M. Abdalla, U. Abdelnaby, and A. A. Mitkees. "Compact and triple band meta-material antenna for all WiMAX applications." In IEEE 2012 International Symposium on Antennas and Propagation (ISAP), pp. 1176-1179.

31. M. A. Abdalla, Z. Hu and and Cahyo. Muvianto, "Analysis and design of a triple band metamaterial simplified CRLH cells loaded monopole antenna", International Journal of Microwave and Wireless Technologies, vol. 9, issue, 4, May 2017, pp. 903-913

32. M. A. Abdalla and A. A. Ibrahim, "Simple Mu-Negative Half Mode CRLH Antenna Configuration for MIMO Applications", Radioengineering, vol. 26, no. 1, part I, pp. 4550, April 2017. 